\title{
TECNOLOGIA ENZIMÁTICA: CLASSIFICAÇÃO, IMOBILIZAÇÃO, SUPORTES E APLICAÇÕES
}

\author{
Enzymatic technology: classification, immobilization, supports and \\ applications
}

\author{
Andressa Franco Denti ${ }^{1}$
}

${ }^{1}$ Universidade Regional Integrada do Alto Uruguai e das Missões (URI) - Programa de Pós graduação em Engenharia de Alimentos, Erechim, RS, Brasil.E-mail: andressa.franco98@hotmail.com

Data do recebimento: 10/03/2021 - Data do aceite: 16/06/2021

RESUMO: A busca pela implementação de alternativas sustentáveis, em meio industrial, condiz com os critérios estabelecidos pela química verde, em conjunto com a necessidade de obter produtos específicos, tornando a implementação da tecnologia enzimática uma possibilidade atrativa para as companhias. Biocatalizadores estão de acordo com dez dos doze princípios da química verde. Este fato, em conjunto com as propriedades catalíticas das enzimas, é responsável por processos de catálise seguros, seletivos e sustentáveis, que geram bons resultados industriais. Dessa forma, o objetivo do presente estudo consiste em realizar uma revisão da bibliografia a respeito da aplicação de enzimas como biocatalizadores, suas classificações, métodos de imobilização e funções no setor industrial. A partir do desenvolvimento da pesquisa, pode-se evidenciar as vantagens da aplicação de enzimas como biocatalizadores, gerando menos resíduos e, muitas vezes, reduzindo as rotas de síntese, desse modo associando a prática industrial com os princípios da química verde.

Palavras-chave: Enzimas. Biocatalizadores. Imobilização. Suportes.

ABSTRACT: The search for the implementation of sustainable alternatives in an industrial environment matches the criteria established by the green chemistry, together with the need to obtain specific products, turning the implementation of enzymatic technology an attractive possibility for companies. Biocatalysts are in accordance with ten out of twelve principles of the green chemistry, this fact, together with the catalytic properties of enzymes, 
is responsible for safe, selective and sustainable catalysis processes, which generate good industrial results. Thus, the objective of the present study is to carry out a bibliographic review regarding the application of enzymes as biocatalysts, their classifications, immobilization methods and functions in the industrial sector. From the development of the research, the advantages of applying enzymes as biocatalysts can be evidenced, generating less waste and often reducing the synthesis routes, in such a way associating industrial practice with the principles of green chemistry.

Keywords: Enzymes. Biocatalysts. Immobilization. Supports.

\section{Introdução}

Os princípios da Química Verde começaram a ser desenvolvidos pelos químicos Paul Anastas e John Warner, por volta de 1990, através do programa "Rotas sintéticas alternativas para prevenção de poluição". A partir de então foi desenvolvida a Química Verde, visando ao planejamento, desenvolvimento e a aplicação de processos e produtos sem gerar resíduos poluentes (CASULLO; SOUBIÓN, 2012; GOMES et al., 2018; OUTILI et al., 2020; NAVEENKUMAR; BASKAR, 2021).

A busca pela implementação de alternativas sustentáveis em meio industrial condiz com os critérios estabelecidos pela química verde, em conjunto com a necessidade de obter produtos específicos, torna a implementação da tecnologia enzimática uma possibilidade atrativa para as companhias. Ao contrário dos catalizadores químicos, os biocatalizadores apresentam elevada especificidade, resultando em uma discriminação eficiente de reações e substratos, partes similares das moléculas (regioespecificidade) e isômeros ópticos (estereoespecificidade), além de apresentarem alta atividade de catálise quando em condições brandas de pressão, pH e temperatura (SOUZA et al., 2017; MORSHED et al., 2021).
Biocatalizadores estão de acordo com dez dos doze princípios da química verde, sendo que dois deles não devem ser levados em consideração, pois estão voltados para o produto, e não para o processo. Este fato, em conjunto com as propriedades catalíticas das enzimas, é responsável por processos de catálise seguros, seletivos e sustentáveis, que geram bons resultados industriais (SHELDON; BRADY, 2019).

Tratando-se de síntese orgânica, as rotas podem ser realizadas por catalizadores químicos ou biológicos, cada um apresentando suas vantagens e desvantagens quanto à aplicação. Em relação à sustentabilidade e processos ecologicamente agradáveis, os biocatalizadores apresentam diversas vantagens, uma vez que reduzem a geração de resíduos e são obtidos através de fontes renováveis e reagem em meios não tóxicos como a água (TEIXEIRA; MILAGRE, 2020).

O termo "enzima" foi usado pela primeira vez pelo fisiologista Wilhelm Kühne, no ano de 1878, quando descreveu a produção de álcool através de açúcar. Entre os séculos XIX e XX foram realizados grandes avanços na área de extração enzimática e em 1920 foi descoberto o poder de catálise das enzimas. Até o ano de 1980 acreditava-se que todas as enzimas eram proteínas. Entretanto, em 1980, foi comprovado que alguns ácidos ribonucleicos também eram capazes de rea- 
lizar atividade catalítica. Na mesma década, bioquímicos desenvolveram uma tecnologia capaz de gerar anticorpos que possuem propriedades catalíticas, com potencial aplicação industrial e terapêutica (ROBINSON, 2015).

De acordo com a ciência química e biológica, enzimas são proteínas (exceto pelas ribozimas, originadas de aminoácidos ligados através de ligações peptídicas) que agem como biocatalizadores de processos biológicos e químicos, decompondo moléculas complexas em menores unidades (QUEIROZ; SOUSA, 2020). Sendo sintetizadas pelas células, as enzimas estão aptas a acelerar biotransformações em organismos vivos. Quando avaliadas em relação à sua aplicabilidade industrial, apresentam vantagens como a alta qualidade do produto formado, menor uso de energia e menores perdas, sendo conhecidas como catalizadores ecológicos que satisfazem os conceitos da química verde (DE SOUZA, 2014; MORSHED et al., 2021).

Apresentam uma estrutura molecular complexa, que compreende uma parte proteica, geralmente integrada com outras moléculas de lipídios ou carboidratos. As enzimas dispõem de uma estrutura primária relacionada à sequência de seus aminoácidos e a uma estrutura secundária da relação destes com os aminoácidos adjacentes, que formam arranjos folha $\beta$ ou $\alpha$-hélice. Quanto à estrutura terciária, a mesma representa as relações entre aminoácidos não próximos, gerando dobramentos. Por fim, a estrutura quaternária compreende a interação com as cadeias polipeptídicas (SANT'ANNA JUNIOR, 2001; ORLANDELLI et al., 2012).

De acordo com Robinson (2015), enzimas são consideradas biocatalizadores, responsáveis pela aceleração de reações bioquímicas em organismos vivos, podendo ser extraídas de células e usadas na catálise de diversos processos comerciais.

A produção enzimática pode ocorrer por dois métodos. O primeiro é denominado fer- mentação em estado sólido (FES), onde são empregados substratos sólidos com umidade suficiente para o crescimento do microrganismo, mas sem a presença de água no meio. Esse método de fermentação é aplicado com fungos filamentosos por apresentarem boa tolerância à baixa atividade de água, enzimas como proteases e pectinases são desenvolvidas desse modo (GAMA; AIRES-BARROS, 2003; MONTEIRO; SILVA, 2009; PIRES, VASCONCELOS; PINHEIRO, 2021).

Outro método empregado para a produção de enzimas é a fermentação submersa (FS), onde o microrganismo é inserido na forma de inoculo em um meio líquido, com os nutrientes dissolvidos. Dessa forma é possível controlar a temperatura, $\mathrm{pH}$, agitação e aeração do ambiente. Entre as vantagens desse método de produção está o fácil controle do meio, menor tempo de fermentação e maior produtividade, uma vez que o microrganismo está submerso de forma uniforme absorvendo os nutrientes com maior eficiência (MONTEIRO; SILVA, 2009; YANG et al., 2021).

A partir do grande interesse industrial na área de tecnologia enzimática para a implementação dos princípios da química verde, $\mathrm{o}$ objetivo do presente estudo consiste em realizar uma revisão da bibliografia a respeito da aplicação de enzimas como biocatalizadores, suas classificações, métodos de imobilização e funções no setor industrial.

Para a elaboração da pesquisa foi realizada uma análise da literatura, incluindo artigos científicos, livros e periódicos relativos à área da tecnologia enzimática, com foco na classificação, imobilização, suportes e aplicações.

A preparação do artigo foi realizada em etapas, primeiramente obtendo-se uma questão norteadora, para em seguida ser possível realizar o estudo e sinopse do material adquirido, bem como seus principais pontos de relevância. Por fim, pode-se analisar os textos para a produção dos resultados e conclusões. 


\section{Desenvolvimento}

\section{Classificação de enzimas de acordo com a União Internacional de Bioquímica e Biologia Molecular}

Por suas propriedades únicas, como biodegradabilidade, alta especificidade e boa eficiência catalítica, as enzimas são muito atrativas comercialmente. Cerca de 3700 enzimas já foram catalogadas e são classificadas em 6 grupos pela União Internacional de Bioquímica e Biologia Molecular (NC-IUBMB) (1992). Conforme o substrato e a reação de catálise, essa classificação compreende: Oxirredutases, Transferases, Hidrolases, Liases, Isomerases e Ligases (CARVALHO, 2015; SANTIAGO et al., 2021).

\section{Oxirredutases}

As oxirredutases compreendem a segunda maior classe de enzimas com funções catalíticas (cerca de 25\%), participando de reações de oxidação e redução. Podem ser divididas em quatro grupos: as oxidases, peroxidases e oxigenases (responsáveis por acelerar reações oxidantes irreversíveis) e as desidrogenases (com função de catalisar reações reversíveis) (FONSECA, 2013; BILAL et al., 2021).

Esses biocatalizadores são metaloenzimas, caracterizadas por conter íons metálicos em seus sítios ativos, e podem ser classificados de acordo com a aplicação. As oxirredutases são utilizadas em processos de transferência de elétrons, associados a metais que possuem um par redox de fácil conversão, como por exemplo o cobre. Em razão da conversão $\mathrm{Cu}(\mathrm{I}) / \mathrm{Cu}(\mathrm{II})$, o íon de cobre apresenta-se em vários processos oxidativos biológicos (COMBA et al., 2012).

Enzimas pertencentes ao grupo das oxirredutases, por exemplo as lacases, tirosinases, ligninas e fenoloxidases são geralmente utilizadas para processos ambientais, como na biorremediação de diversos produtos químicos, tal como fenóis e derivados, tintas e produtos farmacêuticos (ZDARTA et al., 2018).

\section{Transferases}

Como o próprio nome já indica, as enzimas denominadas transferases participam da catálise da transferência de grupos entre dois compostos. São responsáveis por realizar a metilação em sistemas biológicos, como também realizar a transferência de nitritos e fosfatos, transferência de resíduos de açúcar pelas glicosiltransferases, além de glicol aldeído e 1,3-di-hidroacetona por transalciolases e transcetolases (MERCOAGRO, 2016).

\section{Hidrolases}

As hidrolases como lipases, proteases, amilases e celulases compreendem a maioria dos biocatalizadores de interesse industrial, representando $75 \%$ das enzimas comercializadas, sendo, deste total, $90 \%$ de origem microbiana. Essas enzimas, quando associadas à água são capazes de promover a quebra de ligações covalentes (LI et al., 2012; MESSIAS et al., 2011).

As proteases são as enzimas microbianas mais utilizadas pela indústria, representando cerca de $40 \%$ do comércio total, seguida pelas amilases, que compreendem cerca de $25 \%$ da produção mundial (TIWARI et al., 2014). As lipases possuem grande destaque nas indústrias de detergentes, farmacêuticas e alimentícias (SINGH et al., 2019; MASOMIAN, 2016). Por fim, as celulases grupo sintetizado majoritariamente por fungos e bactérias, são aplicadas nas indústrias de papel, têxtil e na preparação de biocombustíves a partir de substratos lignocelulósicos (SINGH et al., 2019; GUPTA et al., 2011; PEIXOTO et al., 2021). 


\section{Liases}

As transeliminases ou liases são caracterizadas por romper ligações glicosídicas, gerando galacturonídeos com uma ligação insaturada entre os carbonos 4 ou 5 do final não redutor do ácido galacturônico produzido. Nesta classe estão incluídas as pectina liases que possuem $\mathrm{pH}$ ótimo entre $5,5 \mathrm{e}$ temperatura ótima entre 40 e $50^{\circ} \mathrm{C}$, capazes de quebrar ligações por transeliminação de hidrogênio de carbonos 4 e 5 da pectina. Também compreende as pectato liases com pH ótimo entre 7,5 e 10 e temperatura ótima entre 40 e $50^{\circ} \mathrm{C}$, responsáveis por catalisar a clivagem de ligações $\alpha-1,4$ de ácido péctico por transeliminação (UENOJO; PASTORE, 2007).

\section{Isomerases}

Enzimas denominadas isomerases possuem capacidade de catalisar reações de isomerização. Quando se trata de racemização e epimerização, as mesmas são realizadas por racemases, epimerases e cistransisomerases, que mudam a configuração de duplas ligações. Também se encontram nessa classe as oxiredutases intramoleculares, capazes de interconverter aldoses em cetoses, realizando a oxidação de uma hidroxila desses compostos e a redução da carbonila adjacente, além das transferases intermoleculares ou mutases, responsáveis de mudar apenas a posição de alguns grupos moleculares do substrato (FOOD INGREDIENTS BRASIL, 2011).

\section{Ligases}

As ligases são enzimas que podem catalisar a ligação de duas moléculas, gerando uma nova ligação química, usando para isso energia. Um exemplo são as sintetases na formação do aminoacil-tRNA (SCARSO, 2011).

\section{Imobilização Enzimática}

Em 2017 o mercado mundial de enzimas era responsável por US\$ 7,1 bilhões, com estimativa de alcançar os US\$10,5 bilhões em 2024, apresentando uma taxa de crescimento de 5,7\% ao ano. A Europa se destaca com $1 / 3$ da produção enzimática mundial, onde cerca de $70 \%$ é realizada através de microrganismos (PAPADAKI et al., 2020; RIGO et al., 2021).

Em função de suas propriedades catalíticas, as enzimas desempenham um papel fundamental na indústria de processos, uma vez que são usadas em conversões químicas, biosensores e processos de biorremediação (O'FAGAIN, 2003). Suas vantagens caracterizam-se pela sua alta gama de substratos e reações que podem participar, sem gerar subprodutos (BRADY e JORDAAN, 2009). Entretanto, algumas limitações na aplicação de enzimas são relacionadas por sua baixa estabilidade e dificuldade de separação para o reuso. Dessa forma, a imobilização enzimática se torna uma alternativa para solucionar essas dificuldades e fazer a aplicação de enzimas mais atrativa do ponto de vista industrial (DUTTA, 2008; MAFRA, 2017; FENG et al., 2021).

Dentre os maiores limitantes da aplicação de enzimas está o elevado custo de purificação e produção, além da instabilidade estrutural quando isoladas do meio natural, perda de atividade catalítica pelas condições do processo, gerando um tempo de uso limitado e, por consequência, um alto custo.

A Imobilização é a retenção de uma molécula em um sistema analítico. Sendo assim, através da imobilização é possível reter a enzima em um suporte sólido, que não seja solúvel no meio de reação, ajudando na preservação da seletividade, atividade e estabilidade molecular. Quando imobilizadas, as enzimas apresentam maior resistência ao meio reacional, mudanças de temperatura, 
pH e solventes, além da possibilidade de separação, recuperação, reutilização e aplicabilidade em processos contínuos, vantagens que beneficiam sua aplicação em comparação à sua forma livre (SOUZA et al., 2017).

Para determinar o método mais eficaz para a imobilização, é necessário analisar a aplicação da enzima e as condições operacionais, uma vez que são parâmetros essenciais que terão ligação com o custo final do produto. Dessa forma, pode-se avaliar, dentre as técnicas disponíveis, a que melhor atenderá as necessidades do processo (FERNANDES; LIMA; LOPES, 2010).

Para imobilizar as biomoléculas é necessária a ligação do material biológico (enzima) em uma matriz insolúvel (suporte), de acordo com as propriedades físico-químicas (acidez, basicidade e polaridade) das cadeias laterais dos aminoácidos dos quais são compostas. Assim, a imobilização dependerá dos tipos de ligação que podem ser feitos com o suporte. Essas interações podem ser químicas, a partir da formação de ligações covalentes ou ligações cruzadas, ou por métodos físicos, caracterizados por interações mais fracas, como ligações de hidrogênio, forças de Van der Walls e interações hidrofóbicas entre suporte e enzima. Outras formas de imobilização incluem o encapsulamento da enzima no suporte (FURLANI et al., 2020). As diferentes formas de imobilização enzimática podem ser separadas em quatro grupos: Adsorção, ligação covalente, encapsulamento e ligação cruzada (NGUYEN; KIM, 2017).

\section{Adsorção}

O método de adsorção para a imobilização enzimática é o mais rápido e simples, caracterizado por interações físicas entre suporte e enzima. A atividade apresentada é muito semelhante a da enzima livre, além de ser uma imobilização fácil e de baixo custo. Em função das forças de ligação resultantes da mudança de $\mathrm{pH}$, força iônica e temperatura, a principal desvantagem desse método é o baixo controle desses parâmetros, uma vez que as atrações podem se desfazer facilmente (MARQUES; YAMANAKA, 2008).

\section{Ligação Covalente}

Para as enzimas ligadas ao suporte por ligações covalentes as moléculas biocatalíticas estão ligadas aos grupos reativos do suporte ou através de um grupo funcional, ligado à matriz de forma artificial, por meio de reações químicas. Os suportes podem ser funcionalizados para obter grupamentos químicos responsáveis por imobilizar a enzima na matriz. Uma das técnicas comumente utilizadas é a silanização de esferas de vidro com glutaraldeído (SCHMIDELL et al., 2001; LEMOS, 2018; SRINIVASAN, 2021).

Quando o produto final precisa ser completamente separado do biocatalizador é recomendada a imobilização por ligação covalente, assim a enzima deve apresentar alta estabilidade com o suporte para ser utilizada no processo. Dessa forma é necessária a ativação da matriz adicionando uma função reativa a um polímero, para gerar um processo ativo. Desse modo o rendimento da imobilização é menor quando relacionado ao custo de produção, uma vez que a ligação da enzima com o suporte não é reversível (BRENA, et al., 2006, MESQUITA et al., 2018).

\section{Encapsulamento}

A imobilização por encapsulamento ou confinamento ocorre quanto se utiliza um compartimento com volume definido para proteger as enzimas do ambiente externo (FICANHA et al., 2015). Nesse tipo de imobilização as enzimas ficam retidas dentro de microcápsulas ou membranas semipermeáveis, sem que ocorra ligação entre suporte e enzima. Dessa forma, moléculas menos complexas, como substrato, se propagam no 
meio reacional e encontram o sítio catalítico enzimático, enquanto moléculas complexas, como os biocatalizadores, não conseguem se difundir pela parede, ficando aprisionadas no suporte (ILLANES, 2011; SOUZA et al., 2017; ROSA, 2019).

\section{Ligação cruzada}

Na ligação cruzada as enzimas ligam-se com proteínas inativas ou umas às outras, gerando uma estrutura tridimensional complexa. Entre os ligantes mais aplicados para a ligação cruzada está o glutaraldeído, usado a partir de um método químico e resultando em ligações covalentes entre as enzimas, gerando uma enzima com alta pureza. Entre as desvantagens desse tipo de imobilização está a alta quantidade de biocatalizador empregado, gerando baixa estabilidade e dificultando a aplicação industrial (SHELDON, 2007; KENNEDY; CABRAL, 1987; DE OLIVEIRA, 2012).

\section{Suportes para a imobilização enzimática}

A natureza das ligações entre a enzima e o suporte será responsável pela estabilidade e o grau de confinamento da enzima imobilizada. Dessa forma as características da matriz influenciam diretamente na efetividade da imobilização e nas propriedades químicas, mecânicas e cinéticas (HU et al., 2018). Para a escolha do material é necessário considerar também as propriedades da enzima e do processo, uma vez que ao escolher um material inadequado pode ocorrer a desintegração do suporte e, assim, impossibilitou a purificação dos produtos (MELLER; SZUMSKI; BUSZEWSKI, 2017; SHELDON; VAN PELT, 2013).

Para escolher o melhor suporte para um processo é necessário avaliar suas características físico-químicas e a possibilidade de recuperação da matriz. Dentre essas proprie- dades salientam-se a área superficial, solubilidade, possibilidade de reaproveitamento, permeabilidade, composição, morfologia, resistência e viabilidade econômica. Em geral, eles podem ser categorizados quanto à sua morfologia em materiais porosos, não porosos e de estrutura de gel, e quanto à origem como suportes inorgânicos ou orgânicos (MENDES, DE CASTRO; GIORDANO, 2011).

\section{Origem do suporte}

Os suportes orgânicos podem ser sintéticos ou naturais. Polímeros naturais como polissacarídeos insolúveis em água (colágeno, quitosana, alginato, amido, agarose) são comumente utilizados para imobilização enzimática, formando géis inertes com estruturas químicas que podem ser facilmente ativadas. Matrizes sintéticas apresentam variação nas formas físicas e estruturais que podem ser combinadas para gerar um suporte ideal (SIRISHA et al., 2016; PEREIRA, 2019).

Como suportes orgânicos podem ser citados os polímeros naturais, onde suas principais vantagens são o baixo custo e a facilidade de degradação, não gerando danos ao meio ambiente. Um exemplo é a quitosana, muito empregada devido às diferentes configurações geométricas como pó, hidrogel, escamas, fibras e membranas, além da presença de grupos funcionais que permitem várias técnicas de imobilização (MORAN et al., 2018; PEREIRA, 2015; QUEISSADA; da SILVA, 2020).

A maioria das imobilizações são realizadas a partir de suportes inorgânicos porosos de alto custo, em razão da resistência mecânica e ao ataque microbiano, além da alta área superficial para que ocorra a ligação com a enzima. Para a aplicação industrial geralmente são utilizados suportes inorgânicos, devido às suas características físicas, principalmente relacionadas à estabilidade 
térmica e resistência mecânica e a solventes orgânicos, fácil regeneração e capacidade de preservar sua estrutura em amplas faixas de pressão, $\mathrm{pH}$ e temperatura. Dentre os mais usados estão gel de sílica, vidro, alumina, óxidos metálicos e zircônia (SIRISHA, et al., 2016; PEREIRA, 2019).

\section{Morfologia do suporte}

Outra classificação para os suportes pode ser realizada em função da sua morfologia, sendo fundamental para a possibilidade de imobilização da enzima em seu interior ou superfície sem alterar a estabilidade do biocatalizador. De acordo com a União Internacional de Química Pura e Aplicada (IUPAC), pode-se classificar os materiais em função do diâmetro como microporoso (diâmetro poroso menor que $2 \mathrm{~nm}$ ) mesoporoso (diâmetro entre 2 e $50 \mathrm{~nm}$ ) ou macroporoso (diâmetro > 50 nm) (CARVALHO; LIMA; SOARES, 2015).

Apesar da classificação nos três grupos, salienta-se que todos apresentam poros em escalas nanométricas, sendo dessa forma materiais nanoporosos, que podem ser estruturalmente amorfos, cristalinos ou paracristalinos. Exemplos desses compostos são zeólitas (microporoso), M41S (mesoporoso) e géis (macroporoso). Todas as classes possuem alta eficiência como adsorventes e catalisadores (GUERRA, 2007; CAZULA et al., 2021).

\section{Aplicação industrial}

Tratando-se da aplicação industrial, o custo de uma enzima imobilizada estará relacionado à quantidade de reciclos que poderão ser realizados a partir da mesma, sendo possível calcular a viabilidade do processo a partir da quantidade de produto produzido (kg) pela quantidade de base catalítica empregada $(\mathrm{kg})$. Dessa forma, recomenda-se uma produtividade de 2 a 10 mil quilogra- mas de produto para cada quilograma do biocatalizador imobilizado quando trata-se de produtos produzidos em grande escala, ou 50 a 100 quilogramas de produto para cada quilograma de enzima imobilizada quando a produção apresentar produtos de grande valor agregado, como fármacos (TUFVESSON et al.,2011; BASSO; SERBAN, 2019).

A catálise enzimática é usada na produção farmacêutica em escala industrial. A principal vantagem dos biocatalizadores em relação aos catalizadores químicos convencionais, é a alta seletividade, na qual a enzima catalítica converte substrato em produto, uma vez que é uma característica fundamental em processos farmacêuticos, dado que simplifica as rotas químicas, ocasionando um processo mais viável (HUISMAN; COLLIER, 2013; LI et al., 2012; CHAPMAN, ISMAIL DINU, 2018; WU et al., 2021). Pode-se citar como exemplo a necessidade de introdução e sequente remoção de grupos protetores da atividade medicinal dos ingredientes fármacos. Quando aplicada uma enzima apropriada, é possível descartar estas etapas (HUISMAN; COLLIER, 2013). Outros benefícios da tecnologia enzimática incluem a redução ou eliminação de substâncias agressivas ou da necessidade de alta temperatura, que podem exigir intensas condições de segurança no processo (CHOI; HAN; KIM 2015; CHAPMAN; ISMAIL; DINU, 2018).

O uso de microrganismos na indústria alimentícia, como na preparação de pães, queijos e bebidas alcóolicas é realizada desde tempos antigos. Espécies como Bacillus ( $B$. subtilis, B. amyloliquefaciens, B. licheniformis), Aspergilus (A. niger), Mucor, Serratia e Saccharomyces (S. cerevisiae) são altamente empregadas. As produções de ácidos orgânicos, enzimas, aminoácidos e laticínios como iogurte, queijo e fermentados no geral, além de bebidas alcoólicas, como vinho e cerveja, são realizadas por microrganismos. Dessa forma, a maioria da produção mundial de 
enzimas (cerca de 50\%), é direcionada ao processamento de alimentos. Nesse setor, as enzimas são aplicadas para aumentar a qualidade e a variedade de produtos (SINGH; SINGH; SACHAN, 2019).

A aplicação de enzimas em escala industrial tem crescido em diversos setores produtivos, como por exemplo fármacos, alimentos, biocombustíveis e conversão de gás natural, a partir de processos que não necessitam de alto consumo de energia e evitam a geração de desperdícios, apresentando como vantagens a alta seletividade e sustentabilidade ambiental. Dessa forma, utilização de enzimas para processos industriais é um campo amplo e consistente, que continua em expansão a partir do contínuo desenvolvimento de processos biocatalíticos. Esses avanços permitem a descoberta e aplicação de novas enzimas para reações químicas tradicionais, facilitando e integrando a tecnologia enzimática no campo da síntese química (SCHMID et al., 2002; BASSO; SERBAN, 2019 WU et al., 2021).

\section{Conclusão}

A partir do desenvolvimento da pesquisa, pode-se evidenciar a importância do desenvolvimento de métodos ambientalmente amigáveis para a substituição dos catalizadores químicos convencionais aplicados industrialmente, gerando menos resíduos e muitas vezes reduzindo as rotas de síntese. Dessa forma é possível associar a prática industrial com os princípios da química verde.

A tecnologia enzimática é uma boa alternativa de biocatalizadores, uma vez que não gera resíduos que poderiam ser tóxicos ao ambiente, além de promover a aceleração de reações sem a necessidade de altas condições de pressão ou temperatura, reduzindo custos energéticos. A partir da imobilização no suporte adequado para cada processo, é possível também recuperar e reutilizar a enzima, facilitando e aumentando as vantagens da sua aplicação na área de catálise química.

\section{REFERÊNCIAS}

BASSO, A.; SERBAN, S. Industrial applications of immobilized enzymes. A review. Molecular Catalysis, v. 479, p. 110607, 2019.

BILAL, M.; BAGHERI, A. R.; VILAR, D. S.; ARAMESH, N.; EGUILUZ, K. I. B.; FERREIRA, L. F. R.; ASHRAF, S. S.; IQBAL, H. M. Oxidoreductases as a versatile biocatalytic tool to tackle pollutants for clean environment-a review. Journal of Chemical Technology \& Biotechnology, 2021.

BRADY, D.; JORDAAN, J. Advances in enzyme immobilization. Biotechnology Letters, v. 31, n. 11, p. 1639-1650, 2009.

BRENA, B. M.; BATISTA-VIEIRA, F. Immobilization of Enzymes. Methods in Biotechnology. Immobilization of Enzymes and Cells, p. 15-26, 2006.

CARVALHO, C. F. Caracterização funcional e estrutural de uma enzima lipolítica encontrada na biblioteca metagenômica de solo de Terra Preta de Índio. 2015. 55 f. Tese de doutorado em Microbiologia - Universidade de São Paulo. São Paulo/SP, 2015.

CARVALHO, N. B.; LIMA, Á. S.; SOARES, C. M. Uso de sílicas modificadas para imobilização de lipases. Química Nova, v. 38, n. 3, p. 399-409, 2015. 
CASULLO P, SOUBIRÓN E. Química Verde: Metas, Desafíos y Formas de Contribuir a su Desarrolo desde La Enseñanza Media. In: MOYNA P. et al., Aportes de La Química al Mejoramiento de La Calidad de Vida, p. 15-45, 2012.

CAZULA, B. B.; FONSECA, R. O. D.; NORONHA, F. B.; ALVES, H. J. Desempenho de catalisadores Ni/Si-MCM-41 na reforma a seco do metano para geração de H2: avaliação de TEOS e cinzas de casca de arroz como fontes de sílica no preparo do suporte catalítico. Matéria, v. 26, n. 2, 2021.

CHAPMAN, J.; ISMAIL, A. E.; DINU, C. Z. Industrial applications of enzymes: Recent advances, techniques, and outlooks. Catalysts, v. 8, n. 6, p. 238, 2018.

CHOI, J. M.; HAN, S. S.; KIM, H. S. Industrial applications of enzyme biocatalysis: Current status and future aspects. Biotechnology Advances, v. 33, p. 1443-1454, 2015.

COMBA, P.; MARTIN, B.; MURUGANANTHAM, A.; STRAUB, J. Structure, bonding, and catecholase mechanism of copper bispidine complexes. Inorganic chemistry, v. 51, n. 17, p. 92149225, 2012.

DE OLIVEIRA, R. H. A. Imobilização de $\alpha$-galactosidase de Aspergillus niger em suporte de quitosana por ligação cruzada. 2012. 109 f. Dissertação de mestrado em Engenharia Química Universidade Federal de Uberlândia. Uberlândia/MG, 2012.

de SOUZA VANDENBERGHE, L. P.; de CARVALHO, J. C.; LIBARDI, N.; RODRIGUES, C.; SOCCOL, C. R. Microbial enzyme factories: current trends in production processes and commercial aspects. Agro-Industrial Wastes as Feedstock for Enzyme Production, p. 1-22, 2016.

de SOUZA, R. L. Sistemas aquosos bifásicos formados por constituintes não convencionais para a purificação de enzimas lipolíticas. 2014. 229 f. Tese de doutorado em Engenharia de Processos Universidade Tiradentes. Aracaju/SE, 2014.

DUTTA, R. Fundamentals of Biochemical Engineering. Springer Berlin Heidelberg, v. 306, 2008.

FERNANDES, K. F.; LIMA, C. S.; LOPES, F. M. Técnicas de imobilização de enzimas. Revista Processos Químicos, v. 4, n. 7, p. 53-58, 2010.

FENG, Y.; HU, H.; WANG, Z.; DU, Y.; ZHONG, L.; ZHANG, C.; JIANG, Y.; JIA, S.; CUI, J. Threedimensional ordered magnetic macroporous metal-organic frameworks for enzyme immobilization. Journal of Colloid and Interface Science, v. 590, p. 436-445, 2021.

FERRAZ, J. D. A.; SOUZA, L. O.; SILVA, T. P.; FRANCO, M. Obtenção de Lipases Microbianas: Uma Breve Revisão. RECEN-Revista Ciências Exatas e Naturais, v. 20, n. 1, p. 30-54, 2018.

FICANHA, A. M. M.; NYARI, N. L. D.; LEVANDOSKI, K.; MIGNONI, M. L.; DALLAGO, R. M. Estudo da imobilização de lipase em sílica obtida pela técnica sol-gel. Química Nova, v. 38, n. 3, p. 364-369, 2015.

FONSECA, F. S. A. D. Ecologia química de percevejos da família Phloeidae e oxirredutases de Bacillus safensis isolado do petróleo. 2013. 248 f. Tese de doutorado em Ciências - Universidade Estadual de Campinas. Campinas/SP, 2013.

FOOD INGREDIENTS BRASIL. Enzimas: Natureza e ação nos alimentos. Food Ingredients Brasil, v. 16, p. 26-37, 2011.

FURLANI, I. L.; AMARAL, B. S.; OLIVEIRA, R. V.; CASS, Q. B. Imobilização enzimática: conceito e efeitos na proteólise. Química Nova, v. 43, n. 4, p. 463-473, 2020.

GAMA, M.; AIRES-BARROS, M. R.; CABRAL, J.; Engenharia Enzimática, Lidel: Portugal, 2003. GOMES, R. N.; LIMA, P. S.; KURIYAMA, S. N.; NETO, A. A. F. Desenvolvimento da química verde no cenário industrial brasileiro. Revista Fitos, p. 80-89, 2018. 
GUERRA, E. M. Preparação e caracterização de pentóxido de vanádio mesoporoso e reações de intercalação. 2007. 178 f. Tese de doutorado em Ciências - Universidade de São Paulo, São Paulo/ SP, 2007.

GUPTA, R.; KHASA, Y. P.; KUHAD, R. C. Evaluation of pretreatment methods in improving the enzymatic saccharification of cellulosic materials. Carbohydrate polymers, v. 84, n. 3, p. 1103 1109, 2011.

HU, Y.; DAI, L.; LIU, D.; DU, W.; WANG, Y. Progress \& prospect of metal-organic frameworks (MOFs) for enzyme immobilization (enzyme/MOFs). Renewable and Sustainable Energy

Reviews, v. 91, p. 793-801, 2018.

HUISMAN, G. W.; COLLIER, S. J. On the development of new biocatalytic processes for practical pharmaceutical synthesis. Curr. Opin. Chem. Biol, v. 17, p. 284-292, 2013.

ILLANES, A. Immobilized biocatalysts. In: Comprehensive Biotechnology, 2nd ed. Elsevier B.V., Cap 1, p. 25-38, 2011.

INTERNATIONAL UNION OF BIOCHEMISTRY AND MOLECULAR BIOLOGY

NOMENCLATURE. Enzyme nomenclature 1992, San Diego: IUBMB, p. 862, 1982.

KENNEDY, J. F; CABRAL, J. M. S. Enzyme Immobilization. Enzyme Technology, p. 761, 1987.

LEMOS, G. P. M. Imobilização de enzimas em membranas para hidrólise da lactose. 2018. 34 f.

Trabalho de Conclusão de graduação em Engenharia Química - Universidade Federal do Rio Grande do Sul. Porto Alegre/RS, 2018.

LI, S.; YANG, X.; YANG, S.; ZHU, M.; WANG, X. Technology Prospecting on Enzymes: Application, Marketing and Engineering. Computational and structural biotechnology Jornal, v. 2, n. 3, 2012.

LI, T.; LIANG, J.; AMBROGELLY, A.; BRENNAN, T.; GLOOR, G.; HUISMAN, G.; LALONDE, J.; LEKHAL, A.; MIJTS, B.; MULEY, S. Efficient, chemoenzymatic process for manufacture of the boceprevir bicyclic [3.1.0] proline intermediate based on amine oxidase-catalyzed desymmetrization. JACS Journal of the American Chemical Society, v. 134, p. 6467-6472, 2012.

MAFRA, A. C. O. Engenharia de biocatalisadores aplicada à síntese de CLEAs para a aplicação na conversão multienzimática de sacarose à ácido glucônico e xarope de frutose.

2017. 172 f. Tese de doutorado em Engenharia Química - Universidade Federal de São Carlos. São Carlos/SP, 2017.

MARQUES, P. R. B. D. O.; YAMANAKA, H. Biossensores baseados no processo de inibição enzimática. Química Nova, v. 31 n. 7, p. 1791-1799, 2008.

MASOMIAN, M.; RAHMAN, R. N. Z. R. A.; SALLEH, A. B.; BASRI, M. Analysis of comparative sequence and genomic data to verify phylogenetic relationship and explore a new subfamily of bacterial lipases. PloS one, v. 11, n. 3, e0149851, 2016.

MELLER, K.; SZUMSKI, M.; BUSZEWSKI, B. Microfluidic reactors with immobilized enzymesCharacterization, dividing, perspectives. Sensors and Actuators, B: Chemical, v. 244, p. 84-106, 2017.

MENDES, A. A.; OLIVEIRA, P. C. D.; CASTRO, H. F. D.; GIORDANO, R. D. L. Aplicação de quitosana como suporte para a imobilização de enzimas de interesse industrial. Química Nova, v. 34, n. 5, p. 831-840, 2011.

MERCOAGRO. Os tipos de enzimas e sua aplicação nos alimentos. Feira internacional de negócios, processamento e industrialização de carne, v. 11, p. 40, 2016.

MESQUITA, M. V. N.; DA SILVA GOMES, L.; MATOS, L. F. L.; DE OLIVEIRA, A. B. M.; NUNES, D. B.; CAMBRUSSI, A. N. C. O.; FREITAS, A. R.; RIBEIRO, A. B. Imobilização enzimática em matrizes poliméricas. Boletim Informativo Geum, v. 9, n. 2, p. 38-50, 2018. 
MESSIAS, J. M.; COSTA B. Z. DA; LIMA, V. M. G. DE; GIESE, E. C.; DEKKER, R. F. H.; BARBOSA, A. M. Lipases microbianas: Produção, propriedades e aplicações biotecnológicas. Semina: Ciências Exatas e Tecnológicas, v. 32, n. 2, p. 213-234, 2011.

MONTEIRO, V. N.; do NASCIMENTO SILVA, R. Aplicações industriais da biotecnologia enzimática. Revista Processos Químicos, v. 3, n. 5, p. 9-23, 2009.

MORAN, H. B. T.; TURLEY, J. L.; ANDERSSON, M.; LAVELLE, C. L. Immunomodulatory properties of chitosan polymers. Biomaterials, v. 184, p. 1-9, 2018.

MORSHED, M. N.; BEHARY, N.; BOUAZIZI, N.; JINPING, G. U. A. N.; NIERSTRASZ, V. A. An overview on biocatalysts immobilization on textiles: preparation, progress and application in wastewater treatment. Chemosphere, v. 279, p. 13081, 2021.

NAVEENKUMAR, R.; BASKAR, G. Process optimization, green chemistry balance and technoeconomic analysis of biodiesel production from castor oil using heterogeneous nanocatalyst. Bioresource Technology, v. 320, p. 124347, 2021.

NGUYEN, H. H.; KIM, M. An overview of techniques in enzyme immobilization. Applied Science and Convergence Technology, v. 26, n. 6, p. 157-163, 2017.

O'FAGAIN, C. Enzyme stabilization - recent experimental progress. Enzyme and Microbial Technology, v. 33, n. 2, p. 137-149, 2003.

ORLANDELLI, R. C.; SPECIAN, V.; FELBER, A. C.; PAMPHILE, J. A. Enzimas de interesse industrial: produção por fungos e aplicações. SaBios-Revista de Saúde e Biologia, v. 7, n. 3, p. 97 $109,2012$.

OUTILI, N.; HALIMA, K.; CHAHRA, N.; RAYAN, M.; HASSEN, M. A. Biodiesel production optimization from waste cooking oil using green chemistry metrics. Renewable Energy, v. 145, p. 2525-2586, 2020.

PAPADAKI, E.; KONTOGIANNOPOULOS, N. K.; ASSIMOPOULOU, A. N.;

MANTZOURIDOU, F. T. Feasibility of multi-hydrolytic enzymes production from optimized grape pomace residues and wheat bran mixture using Aspergillus niger in an integrated citric acidenzymes production process. Bioresource Technology, v. 309, p. 123317, 2020.

PEIXOTO, F. B. S.; da CUNHA PEIXOTO, J. C.; SARAIVA, A. B. F.; RUIZ, M. M.; PEIXOTO, A. T. M.; PEREIRA, J. O.; ASTOLFI-FILHO, S. Microrganismos isolados de ambientes aquáticos da amazônia produtores de hidrolases de interesse industrial e biotecnológico. Revista GEINTECGestão, Inovação e Tecnologias, v. 11, n. 1, p. 5795-5808, 2021.

PEREIRA, M. B. Imobilização de biocatalisadores para hidrólise enzimática de materiais lignocelulósicos. 2019. 78 f. Dissertação de mestrado em Engenharia Química - Universidade Federal de Goiás, Goiânia/GO, 2019.

PEREIRA, R. M. Obtenção, caracterização e utilização de hidrogel de quitosana e glicerol fosfato para imobilização de lipase de Rhizopus oryzae. 2015. 69 f. Dissertação de mestrado em Ciência e Engenharia de Materiais - Universidade Federal de Alfenas, Poços de Caldas/MG, 2015.

PIRES, G. B.; VASCONCELOS, P. G.; PINHEIRO, I. R. Comparação da fermentação semisólida em casca de cacau para produção de celulases em diferentes escalas de processos. Revista Multidisciplinar de Educação e Meio Ambiente, v. 2, n. 1, p. 11, 2021.

QUEIROZ, C.; de SOUSA, A. C. B. Produção de enzimas hidrolíticas por fungos filamentosos em diferentes substratos sólidos. Brazilian Journal of Development, v. 6, n. 7, p. 51849-51860, 2020.

QUEISSADA, D. D.; DA SILVA, J. A. Imobilização enzimática em suportes orgânicos e inorgânicos: vantagens e desvantagens. Holos Environment, v. 20, n. 2, p. 271-286, 2020. 
RIGO, D.; GAYESKI, L.; TRES, G. A.; CAMERA, F. D.; ZENI, J.; VALDUGA, E.; CANSIAN R. L.; BACKES, G. T. Produção Microbiológica de Enzimas: uma Revisão. Brazilian Journal of Development, v. 7, n. 1, p. 9232-9254, 2021.

ROBINSON, P. K. Enzymes: principles and biotechnological applications. Essays in biochemistry, v. 59, p. 1-41, 2015.

ROSA, C. M. R. Síntese e caracterização de partículas poliméricas à base de estireno com propriedades magnéticas para utilização como matriz de imobilização de enzimas.2019. $132 \mathrm{f}$. Dissertação de mestrado em Ciências - Universidade de São Paulo. Lorena/SP, 2019.

SANT'ANNA JUNIOR, G. L. Produção de enzimas microbianas. In: LIMA, U. A.; AQUARONE, E.; BORZANI, W.; SCHMIDELL, W. (coord.). Biotecnologia industrial: processos fermentativos e enzimáticos. São Paulo: Edgard Blücher Ltda., p. 351- 362, 2001.

SANTIAGO, P. A. L.; DA SILVA SANTIAGO, S. R. S.; DOS SANTOS GOMES, A. M.; SANTO PEREIRA, K. D. D. E.; DA COSTA BARROSO, J.; LIMA, Y. V. V.; DE OLIVEIRA, E. C. A. Avaliação enzimática e morfológica de fungos associados a um basidiomiceto da região Amazônica. Brazilian Journal of Development, v. 7, n. 1, p. 9831-9850, 2021.

SCARSO, M. E. Identificação e caracterização do papel da glutamil-tRNA sintetase na localização de proteínas cloroplásticas. 2011. 70 f. Dissertação de mestrado em Ciências Universidade de São Paulo São Paulo/SP, 2011.

SCHMID, A.; HOLLMANN, F.; PARK, J. B.; BÜHLER, B. The use of enzymes in the chemical industry in Europe. Current Opinion in Biotechnology, v. 13, n. 4, p. 359-366, 2002.

SCHMIDELL, W.; LIMA, U. A.; AQUARONE, E.; BORZANI, W. Biotecnologia industrial. Volume II. Editora Edgard Blucher LTDA, 2001.

SHELDON, R. A. Adv. Synth. Catal. v. 349, p. 1289, 2007.

SHELDON, R. A.; BRADY, D. Broadening the scope of biocatalysis in sustainable organic synthesis. ChemSusChem, v. 12, n. 13, p. 2859-2881, 2019.

SHELDON, R. A.; VAN PELT, S. Enzyme immobilisation in biocatalysis: why, what and how. Chemical Society Reviews, v. 42, n. 42, p. 6223-6235, 2013.

SINGH, R. S.; SINGH, T., PANDEY, A. Microbial Enzymes: An Overview. In: SINGH, R. A.; SINGHANIA, R. R.; PANDEY, A.; LARROCHE, C. Advances in Enzyme Technology. 1. ed. Elsevier, p. 1-40, 2019.

SINGH, R.; SINGH, A.; SACHAN, S. Enzymes used in the food industry: Friends or foes? In: Enzymes in food biotechnology, p. 827-843. Academic Press, 2019.

SIRISHA, V. L.; ANKITA J.; AMITA J. Enzyme Immobilization: Na Overview on Methods, Support Material, and Applications of Immobilized Enzymes. Advances in Food and Nutrition Research. v. 79, 2016.

SOUZA, L. T.; VERÍSSIMO, L. A.; PESSELA, B. C.; SANTORO, R. R.; RESENDE, R. R.; MENDES, A. A. Imobilização enzimática: princípios fundamentais e tipos de suporte. In: Resende, R. R. Biotecnologia aplicada à agro\&indústria: fundamentos e aplicações, v. 4. Editora Blucher, 2017. SRINIVASAN, B. Words of advice: teaching enzyme kinetics. The FEBS Journal, v. 288, n. 7, p. 2068-2083, 2021.

TEIXEIRA, I. S.; MILAGRE, C. D. Evolução dirigida de enzimas: pequenas modificações, melhores biocatalisadores. Química Nova, v. 43, n. 6, p. 773-786, 2020.

THE NOVOZYMES REPORT. 2016. Disponível em: https://report2016.novozymes.com/-/media/ Account-PDF/PDF section/NovozymesReport2016.ashx. Acesso em: 09 fev.2021. 
TIWARI, S.; SHUKLA, N.; MISHRA, P.; GAUR, R. Enhanced Production and Characterization of a Solvent Stable Amylase from Solvent Tolerant Bacillus tequilensis RG-01: Thermostable and Surfactant Resistant. The Scientific World Journal, v. 11, 2014.

TUFVESSON, P.; LIMA-RAMOS, J.; NORDBLAD, M.; WOODLEY, J. M. Guidelines and cost analysis for catalyst production in biocatalytic processes. Organic Process Research $\&$ Development, v. 15, n. 1, p. 266-274, 2011.

UENOJO, M.; PASTORE, G. M. Pectinases: aplicações industriais e perspectivas. Química Nova, v. 30, n. 2, p. 388-394, 2007.

WU, S.; SNAJDROVA, R.; MOORE, J. C., BALDENIUS, K.; BORNSCHEUER, U. T. Biocatalysis: enzymatic synthesis for industrial applications. Angewandte Chemie International Edition, v. 60, n. 1, p. 88-119, 2021.

YANG, X.; YANG, Y.; ZHANG, Y.; HE, J.; XIE, Y. Enhanced exopolysaccharide production in submerged fermentation of Ganoderma lucidum by Tween 80 supplementation. Bioprocess and Biosystems Engineering, v. 44, n. 1, p. 47-56, 2021.

ZDARTA, J.; MEYER, A. S.; JESIONOWSKI, T.; PINELO, M. Developments in support materials for immobilization of oxidoreductases: A comprehensive review. Advances in colloid and interface science, v. 258, p. 1-20, 2018. 